\title{
RESEARCH
}

Open Access

\section{Risk factors for the accuracy of the initial diagnosis of malaria cases in China: a decision-tree modelling approach}

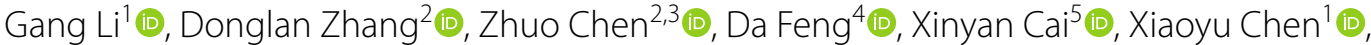 \\ Shangfeng Tang ${ }^{1}\left(\mathbb{D}\right.$ and Zhanchun Feng ${ }^{1 *}$ (D)
}

\begin{abstract}
Background: Early accurate diagnosis and risk assessment for malaria are crucial for improving patients'terminal prognosis and preventing them from progressing to a severe or critical stage. This study aims to describe the accuracy of the initial diagnosis of malaria cases with different characteristics and the factors that affect the accuracy in the context of the agenda for a world free of malaria.

Methods: A retrospective study was conducted on 494 patients admitted to hospitals with a diagnosis of malaria from January 2014 through December 2016. Descriptive statistics were calculated, and decision tree analysis was performed to predict the probability of patients who may be misdiagnosed.

Results: Of the 494 patients included in this study, the proportions of patients seeking care in county-level, prefecture-level and provincial-level hospitals were $27.5 \%(n=136), 26.3 \%(n=130)$ and $8.3 \%(n=41)$, respectively; the proportions of patients seeking care in clinic, township health centre and Centres for Disease Control and Prevention were $25.9 \%(n=128), 4.1 \%(n=20)$, and $7.9 \%(n=39)$, respectively. Nearly $60 \%$ of malaria patients were misdiagnosed on their first visit, and $18.8 \%$ had complications. The median time from onset to the first visit was 2 days (IQR: 0-3 days), and the median time from the first visit to diagnosis was 3 days (IQR: 0-4 days). The decision tree classification of malaria patients being misdiagnosed consisted of six categorical variables: healthcare facilities for the initial diagnosis, time interval between onset and initial diagnosis, region, residence type, insurance status, and age.
\end{abstract}

Conclusions: Insufficient diagnostic capacity of healthcare facilities with lower administrative levels for the first visit was the most important risk factor in misdiagnosing patients. To reduce diagnostic errors, clinicians, government decision-makers and communities should consider strengthening the primary care facilities, the time interval between onset and initial diagnosis, residence type, and health insurance status.

Keywords: Geographic variation, Health seeking behaviour, Healthcare institutions, Decision tree

\footnotetext{
*Correspondence: zcfeng@hust.edu.cn

${ }^{1}$ School of Medicine and Health Management, Tongji Medical College, Huazhong University of Science and Technology, 430030 Wuhan, Hubei, China

Full list of author information is available at the end of the article
}

\section{Background}

Malaria is a major infectious disease that continues to present challenges to population health and healthcare systems worldwide, particularly in developing countries $[1,2]$, where it is a major cause of mortality and morbidity $[1,3]$. According to the latest data, an estimated 229 million malaria cases and 409,000 deaths occurred globally in 2019 [3]. China was once a major malaria-endemic original author(s) and the source, provide a link to the Creative Commons licence, and indicate if changes were made. The images or other third party material in this article are included in the article's Creative Commons licence, unless indicated otherwise in a credit line to the material. If material is not included in the article's Creative Commons licence and your intended use is not permitted by statutory regulation or exceeds the permitted use, you will need to obtain permission directly from the copyright holder. To view a copy of this licence, visit http://creativecommons.org/licenses/by/4.0/. The Creative Commons Public Domain Dedication waiver (http://creativeco mmons.org/publicdomain/zero/1.0/) applies to the data made available in this article, unless otherwise stated in a credit line to the data. 
country, but the Chinese Government has made great strides in preventing and controlling malaria [4]. After 70 years, there has been no report of autochthonous malaria cases for nearly four consecutive years, since 2017 [5, 6], meeting the goal of malaria elimination set by the World Health Organization [7, 8].

With the sharp increase in international travel among Chinese people, the risk of imported malaria cases from malaria-endemic areas threatens the maintenance of the malaria elimination goal of China [9]. Among imported malaria cases, Plasmodium falciparum is the most common species, with potentially fatal outcomes [10]. The fatality of malaria cases in China is rising, with more than four-fifths of deaths associated with severe complications, such as severe brain/liver/kidney lesions, shock, and haemolysis $[11,12]$.

It is recommended that all malaria cases be treated effectively and affordably within $24 \mathrm{~h}$ of onset [13]. However, not all patients can get a timely and accurate diagnosis. Most cases of "malaria" (i.e., having a fever) are self-diagnosed, and most treatments and deaths occur at home [14]. Early and accurate diagnosis and risk assessment for malaria is crucial for improving patients' terminal prognosis and preventing them from progressing to the severe or critical state [15]. In addition, it also helps to reduce the direct or indirect treatment costs for patients and the risk of community transmission [16].

To date, studies identified some factors associated with the misdiagnosis of malaria, including insufficient diagnostic equipment, means of diagnosis, lack of clinical supervision/training for local clinicians, lack of malariarelated knowledge for travellers, Plasmodium species, and health system factors [17-24]. However, most of these have been carried out in a few malaria-endemic developing countries or in just one province of China [25]. Studies on misdiagnosis of malaria using samples from multiple provinces and rich clinical medical records in China are limited. This study aims to identify factors associated with the misdiagnosis of malaria and develop a predictive model based on the medical records to guide prevention and reduce misdiagnoses.

\section{Methods}

\section{Study design and site}

A multi-stage sampling approach was adopted to obtain the study population. In each region of China, two provinces with the highest incidence of malaria were selected, including Zhejiang and Jiangsu in Eastern China, Henan and Anhui in Central China, and Yunnan and Sichuan in Western China [26]. A preliminary analysis was conducted on the number of malaria cases reported by different levels of hospitals based on the data provided by the National Health Commission. It was found that most county-level hospitals reported fewer than two cases, and most cases were reported in the higher level of hospitals. Then two provincial-level hospitals, five prefecture-level hospitals, 10 county-level hospitals with relatively large numbers of malaria cases in each province were selected according to the hospitals' lists of reported malaria cases during 2014-2016, and the cluster sampling method was used to collected patients' medical records in each selected hospital. According to the sampling design, a total of 1,868 cases from 102 hospitals should be investigated. In fact, 1,633 cases were collected from 63 hospitals because some hospitals surveyed refused to provide medical records. After screening the completeness of patients' medical records reported by each hospital, 494 cases from 26 hospitals were finally included in this analysis.

Figure 1 shows the geographic distribution of the six selected provinces. Jiangsu and Zhejiang provinces are geographically in proximity to the East China Sea, considered one of the most developed regions in the country and has frequent trade exchanges with other countries. Henan and Anhui are China's inland provinces, bordering each other, with flat terrain. High-speed rail and highways pass through these two provinces connecting with most other provinces in the country. Sichuan and Yunnan are mountainous and relatively underdeveloped areas located in Southwestern China. Transport infrastructure and medical facilities are relatively scarce in these two provinces [27].

\section{Data collection}

This is a retrospective study of 494 patients admitted to hospitals with a diagnosis of malaria from January 2014 through December 2016. These patients were confirmed to be positive for Plasmodium species by rapid diagnostic tests (RDTs), microscopy or polymerase chain reaction (PCR). Data were obtained from the patients' medical records using a protocol designed for the study. Demographic, epidemiological and clinical data were collected from medical records, including age, gender, occupation, education, residence type, health insurance status, detailed course from the onset of symptoms to seeking medical services, treatment details, co-morbidities, outcome (cure or death), as well as blood chemicals and microbiology analyses.

\section{Definitions}

China has five levels of administrative divisions: provincial, prefectural, county, township, and village. There are two main types of health facilities in China [28]. One is a professional public health agency, such as various levels of Centre for Disease Control and Prevention (CDC), which undertake surveillance and detection of infectious 


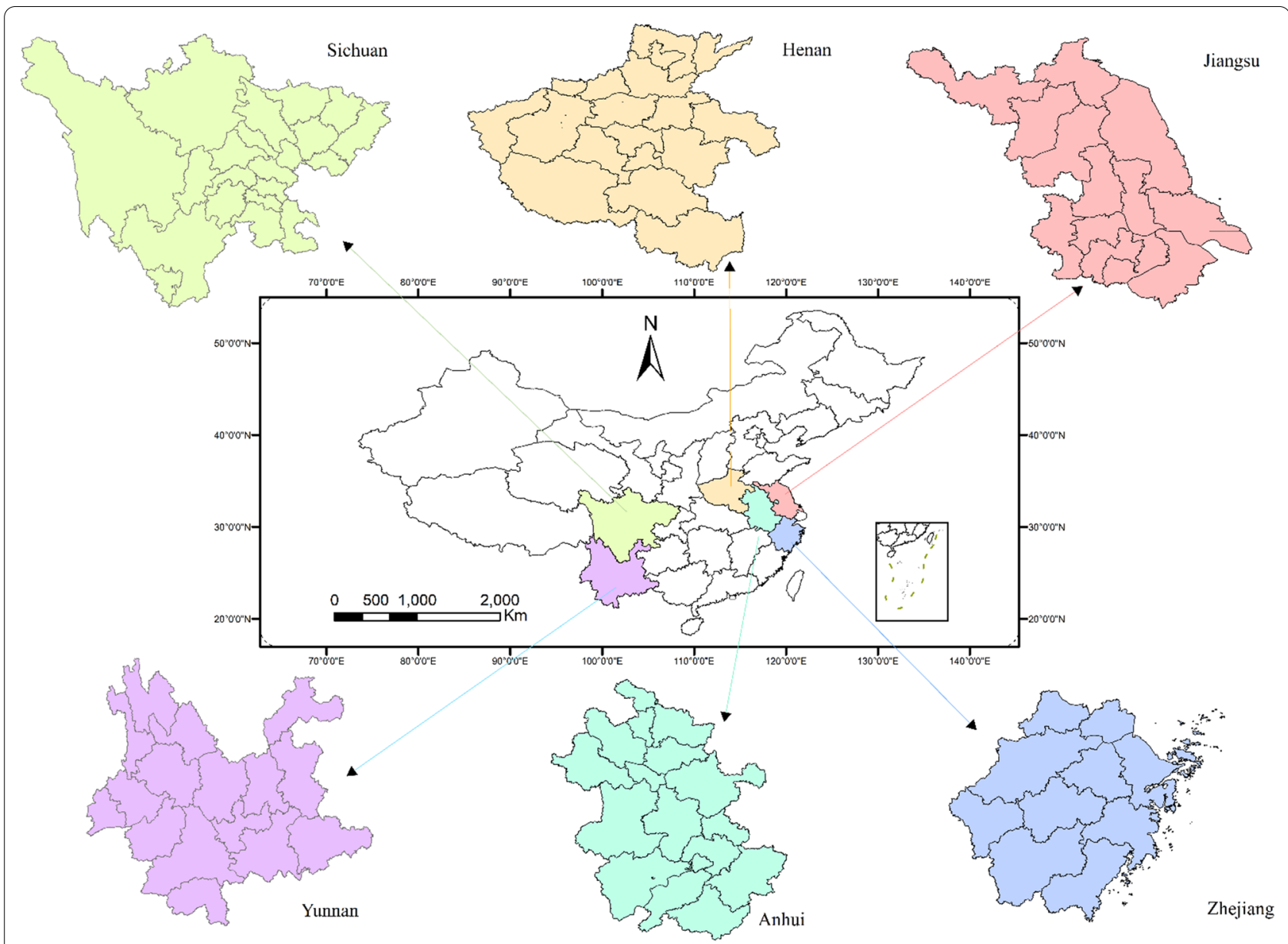

Fig. 1 Geographic distribution of the six selected provinces in China

disease, prevention of chronic disease and distribution of certain free medications, including anti-malarial drugs. The other type of facility are institutions that provide treatment services, including hospitals, township health centres and village clinics. CDCs and hospitals can be divided into three levels: provincial, prefectural and county level, aligned with the administrative levels. Township health centres and clinics are generally set up within the jurisdiction of townships and villages. In most cases, medical facilities with higher administrative levels also have higher diagnostic and treatment capabilities.

\section{Statistical analysis}

The descriptive statistics, Chi-square and t-test analyses were performed with Stata version 15.0 (StataCorp, College Station, TX, USA). Descriptive statistics were used to summarize the sociodemographic characteristics. Statistical significance was defined as a p-value $<0.05$. Decision tree analysis using the IBM SPSS Statistics 25.0 (IBM Corp, Armonk, NY, USA) was performed to build an optimum and significant predictive model to predict the probabilities of misdiagnosing patients. The classification and regression tree (CART) techniques were conducted to obtain the best cut-off points in the software $[29,30]$. The initial diagnosis (misdiagnosis/correct diagnosis) was treated as a dependent variable, and demographic and clinical characteristics variables (age, gender, marital status, occupation, residence type, region, insurance status, Plasmodium species, time interval between onset and initial diagnosis, healthcare facilities for initial diagnosis) were treated as as independent variables in the model. Parameters of the final CART model were set as follows: maximum tree depth was five, with minimum cases in parent node as 10 and in child node as five.

\section{Ethical approval and consent}

The study was approved by the Ethics Committee of the Tongji Medical College of Huazhong University of Science and Technology (IORG0003571). Written permission to access and analyse the research data 
was granted by the National Health Commission of the People's Republic of China and the administrators of each hospital. Patient information was anonymized and de-identified.

\section{Results}

\section{Sociodemographic characteristics}

The demographic and clinical characteristics of patients are summarized in Table 1. The median age of the 494 patients was 39 years (range: 11-63 years), and most were male (98.2\%). Of these individuals, around $80 \%$ were married, $62 \%$ lived in rural areas, $35 \%$ were employed in agriculture, and $70 \%$ had health insurance. The malaria cases were mostly from Plasmodium falciparum: 62.4\% $(\mathrm{n}=308)$, and cases due to Plasmodium vivax, Plasmodium ovale, and Plasmodium malariae were 19.2\% $(\mathrm{n}=95), 3.0 \%(\mathrm{n}=15)$, and $0.6 \%(\mathrm{n}=3)$, respectively.

\section{Health-seeking behaviour}

The proportions of patients seeking care in county-level, prefecture-level and provincial-level hospital were $27.5 \%$ $(\mathrm{n}=136), 26.3 \%(\mathrm{n}=130)$ and $8.3 \%(\mathrm{n}=41)$, respectively; the proportions of patients seeking care in clinic, township health centre, and CDC were $25.9 \%(\mathrm{n}=128)$, $4.1 \%(\mathrm{n}=20)$ and $7.9 \%(\mathrm{n}=39)$, respectively. Nearly $60 \%$ of malaria patients were misdiagnosed on their first visit, and concerning complications affected 18.8\% of the patients. Approximately half of the patients were admitted to the hospital via emergency rooms. Patients with fever, chills and sweating upon admission were 99.4\% $(\mathrm{n}=491), 42.3 \%(\mathrm{n}=209)$, and 38.7\% $(\mathrm{n}=191)$, respectively.

Median time intervals were as follows: from onset to the first medical visit, 2 days (IQR: $0-3$ days); from the first medical visit to diagnosis, 3 days (IQR: 0-4 days); and, from onset to final diagnosis, 5.5 days (IQR: $2-10$ days). Table 2 shows the time interval from symptom onset to initial diagnosis, and from initial diagnosis to final diagnosis of malaria cases in multiple healthcare institutions. The time interval between onset and initial diagnosis in the provincial-level, prefecture-level and county-level hospitals was 3.3 days, 2.4 days and 2.2 days, respectively, which was longer than in other healthcare institutions. The time interval from the initial diagnosis to the final diagnosis in prefecture-level, provincial-level and county-level CDCs was 0.5 days, 1.0 days and 1.1 days, respectively, followed by provincial-level hospitals (1.1 days) and prefecture-level hospitals (1.3 days). However, the time interval from the initial diagnosis to the final diagnosis in village clinics, county-level hospitals and township health centres was much longer at 5.8 days, 4.8 days and 4.0 days, respectively.

\section{Factors influencing initial diagnosis and malaria complications}

Demographic and epidemiological factors influencing initial diagnosis are shown in Table 3 . There was a significant difference in misdiagnosis rate for the initial diagnosis between different regions, Plasmodium species and healthcare facilities. Among patients from Western China, around $67.5 \%(\mathrm{n}=79)$ of patients were not correctly diagnosed; misdiagnosis rates in Central and Eastern China were $58.8 \%(\mathrm{n}=163)$ and $34.3 \%$ $(\mathrm{n}=23)$, respectively. Among all mixed malaria cases, $80.0 \%(n=4)$ were not correctly diagnosed at the first medical visit. The misdiagnosis rates of mixed, unclassified, $P$. ovale, $P$. falciparum, $P$. vivax, and $P$. malariae were $80.0,71.7,68.5,51.4,46.7$, and $33.3 \%$, respectively. Notably, the misdiagnosis rate was up to $100 \%$ at clinics and township health centres, and $68.5 \%$ in county-level hospitals during their first medical visit. More generally, the rate of misdiagnosis decreased with the level and quality of health institutions.

No patients infected with $P$. malariae and mixed species developed complications. Nearly $20 \%$ of patients infected with $P$. falciparum had complications. Except for prefecture-level hospitals, the incidence of complications was relatively low for patients whose first visit was at a higher administrative level of healthcare institution. There were $0,4.9$ and $8.1 \%$ complications in patients initially visiting provincial-level CDCs, provincial-level hospitals and county-level hospitals, respectively. In contrast, there were $28.1,26.9$ and $20.0 \%$ complications in patients initially visiting village clinics, prefecture-level hospitals and township health centres, respectively. The proportion of complications in patients with a correct initial diagnosis was $13.3 \%$, whereas, it was $23.3 \%$ in patients with an incorrect initial diagnosis. Furthermore, malaria patients with complications tended to have a significantly longer time interval between onset and initial diagnosis (Table 4).

\section{Decision tree classifier model}

Figure 2 shows the decision tree classification of malaria patients being misdiagnosed. This model was useful to identify the risk factors with the introduction of sub-groups with similar risk levels and the risk factors for initial misdiagnosis in the studied patients. The decision tree classification of malaria patients being misdiagnosed consisted of six categorical variables that ranked by their importance: level of healthcare facilities for the initial diagnosis, time interval between onset and initial diagnosis, region, residence type, insurance status, and age. The accuracy of the prediction model was $85.0 \%$. 
Table 1 Epidemiological characteristics of individuals with imported malaria

\begin{tabular}{|c|c|}
\hline Factors & Number (\%) \\
\hline \multicolumn{2}{|l|}{ Gender $(n=494)$} \\
\hline Male & $485(98.2 \%)$ \\
\hline Female & $9(1.8 \%)$ \\
\hline \multicolumn{2}{|l|}{ Age (years) $(n=494)$} \\
\hline$<35$ & $205(41.5 \%)$ \\
\hline$\geq 35$ & $289(58.5 \%)$ \\
\hline \multicolumn{2}{|l|}{ Marital Status $(n=494)$} \\
\hline Married & $394(79.8 \%)$ \\
\hline Single/divorce/separated & $100(20.2 \%)$ \\
\hline \multicolumn{2}{|l|}{ Occupation $(n=494)$} \\
\hline Agriculture & $170(34.4 \%)$ \\
\hline No-agriculture & $324(65.6 \%)$ \\
\hline \multicolumn{2}{|l|}{ Residence $(n=489)$} \\
\hline Rural & $304(62.2 \%)$ \\
\hline Urban & $185(37.8 \%)$ \\
\hline \multicolumn{2}{|l|}{ Region $(n=494)$} \\
\hline Eastern & $67(13.6 \%)$ \\
\hline Central & $309(62.6 \%)$ \\
\hline Western & $118(23.9 \%)$ \\
\hline \multicolumn{2}{|l|}{ Plasmodium species $(n=494)$} \\
\hline Unclassified & $68(13.8 \%)$ \\
\hline Plasmodium falciparum & $308(62.4 \%)$ \\
\hline Plasmodium ovale & $15(3.0 \%)$ \\
\hline Plasmodium vivax & 95 (19.2\%) \\
\hline Plasmodium malariae & $3(0.6 \%)$ \\
\hline Mixed & $5(1.0 \%)$ \\
\hline \multicolumn{2}{|c|}{ Rank of healthcare facilities for the initial diagnosis $(n=494)$} \\
\hline Village clinic & $128(25.9 \%)$ \\
\hline Township health center & $20(4.1 \%)$ \\
\hline County-level CDC & $22(4.5 \%)$ \\
\hline Prefecture-level CDC & $15(3.0 \%)$ \\
\hline Provincial-level CDC & $2(0.4 \%)$ \\
\hline County-level hospital & $136(27.5 \%)$ \\
\hline Prefecture-level hospital & $130(26.3 \%)$ \\
\hline Provincial-level hospital & $41(8.3 \%)$ \\
\hline \multicolumn{2}{|l|}{ Initial diagnosis $(n=461)$} \\
\hline Misdiagnosis & $265(57.5 \%)$ \\
\hline Correct diagnosis & $196(42.5 \%)$ \\
\hline \multicolumn{2}{|l|}{ Admission pathway $(n=494)$} \\
\hline Emergency & $244(49.4 \%)$ \\
\hline Outpatient & $242(49.0 \%)$ \\
\hline Referral & $8(1.6 \%)$ \\
\hline \multicolumn{2}{|l|}{ Symptom $(n=494)$} \\
\hline Fever & $491(99.4 \%)$ \\
\hline Chills & $209(42.3 \%)$ \\
\hline Sweating & $191(38.7 \%)$ \\
\hline Splenomegaly & $7(1.4 \%)$ \\
\hline Anemia & $41(8.3 \%)$ \\
\hline Periodic & $123(24.9 \%)$ \\
\hline
\end{tabular}


Table 1 (continued)

\begin{tabular}{lc}
\hline Factors & Number (\%) \\
\hline Complications developed $(n=494)$ & $93(18.8 \%)$ \\
Yes & $401(81.2 \%)$ \\
No & $346(70.0 \%)$ \\
Insurance status $(n=494)$ & $148(30.0 \%)$ \\
$\quad$ Insured & \\
Uninsured & $106(21.8 \%)$ \\
Hospitalization cost (USD) $(n=486)$ & $136(28.0 \%)$ \\
36-500 & $161(33.1 \%)$ \\
501-1000 & $83(17.1 \%)$ \\
1001-2000 & Mean, Median, Min, \\
Days & P10, P25, P75, P90, \\
& \\
Time interval from fever onset toinitial diagnosis & Max \\
Time interval from initial diagnosis to final diagnosis & $2.0,1,0,0,3,5,20$ \\
Time interval from fever onset to final diagnosis & $3.5,2,0,0,4,8,90$ \\
\hline
\end{tabular}

Table 2 Time interval from symptom onset to initial diagnosis, and from initial diagnosis to final diagnosis of malaria cases in multiple healthcare institutions

\begin{tabular}{llc}
\hline Healthcare institutions & $\begin{array}{l}\text { Time interval between onset and initial diagnosis } \\
\text { Mean } \mathbf{( 9 5 \% ~ C l )}\end{array}$ & $\begin{array}{l}\text { Time interval from initial } \\
\text { diagnosis to final diagnosis } \\
\text { Mean } \mathbf{( 9 5 \% ~ C l )}\end{array}$ \\
\hline Village clinic & $1.42(0.92-1.91)$ & $5.80(4.42-7.17)$ \\
Township health center & $1.05(0.28-1.82)$ & $4.00(2.43-5.57)$ \\
County-level CDC & $1.32(0.59-2.05)$ & $1.09(0.11-2.07)$ \\
Prefecture-level CDC & $1.77(0.85-2.68)$ & $0.47(0.09-0.84)$ \\
Provincial-level CDC & $1.25(-0.22$ to 2.72$)$ & $1.00(-0.96$ to 2.96$)$ \\
County-level hospital & $2.21(1.78-2.63)$ & $4.83(3.28-6.38)$ \\
Prefecture-level hospital & $2.40(2.00-2.80)$ & $1.29(0.82-1.77)$ \\
Provincial-level hospital & $3.32(2.09-4.55)$ & $1.12(0.44-1.81)$
\end{tabular}

The decision tree shows that in a sub-group of patients who visited clinics and township health centres for the first time, the probability of a patient being misdiagnosed was $100 \%$. In the sub-group of patients who visited county-level hospitals for the first time, with patients from Eastern China, the probability of being misdiagnosed was $30.8 \%$. In the same situation with patients from Central and Western China, if the time interval between onset and initial diagnosis $>0.5$ days, the probability of being misdiagnosed was $68.4 \%$, while if the time interval between onset and initial diagnosis $\leq 0.5$ days and age $>41.5$ years, there was a $100 \%$ probability of being misdiagnosed. In the sub-group of patients who visited healthcare facilities at county-level and above for the first time, whose time interval between onset and initial diagnosis was $<0.25$ days, and who lived in urban areas, $84.6 \%$ of individuals was misdiagnosed. In the same situation with the time interval between onset and initial diagnosis $>0.25$ days, if the patients sought care at different levels of CDC, $32.0 \%$ of individuals were misdiagnosed.

\section{Discussion}

This study described the accuracy of the initial diagnosis of malaria cases with different characteristics, as well as the factors that affect the accuracy. This study also analysed the importance of misdiagnosis influencing factors through the CART model. It was found that the level of healthcare facility for the initial visit was the most important factor affecting whether malaria patients were correctly diagnosed. The proportion of misdiagnosed 
Table 3 Influential factors of the malaria cases at initial diagnosis

\begin{tabular}{|c|c|c|c|}
\hline \multirow[t]{2}{*}{ Influential factors } & \multicolumn{2}{|c|}{ Initial diagnosis (\% or $95 \% \mathrm{Cl}$ ) } & \multirow[t]{2}{*}{ P-value } \\
\hline & Misdiagnosis(\%) & Correct diagnosis(\%) & \\
\hline \multicolumn{4}{|l|}{ Gender } \\
\hline Male & $259(57.3)$ & $193(42.7)$ & \multirow[t]{2}{*}{0.574} \\
\hline Female & $6(66.7)$ & $3(33.3)$ & \\
\hline Age (years) & $38.4(37.2-39.5)$ & $38.3(37.0-39.6)$ & 0.930 \\
\hline \multicolumn{4}{|l|}{ Marital Status } \\
\hline Married & $217(58.8)$ & $152(41.2)$ & \multirow[t]{2}{*}{0.250} \\
\hline Single/divorce/separated & $48(52.2)$ & $44(47.8)$ & \\
\hline \multicolumn{4}{|l|}{ Occupation } \\
\hline Agriculture & $94(59.1)$ & 65 (40.9) & \multirow[t]{2}{*}{0.606} \\
\hline No-agriculture & $171(56.6)$ & $131(43.4)$ & \\
\hline \multicolumn{4}{|l|}{ Residence } \\
\hline Rural & $161(57.1)$ & $121(42.9)$ & \multirow[t]{2}{*}{0.841} \\
\hline Unban & $101(58.1)$ & $73(42.0)$ & \\
\hline \multicolumn{4}{|l|}{ Region } \\
\hline Eastern & $23(34.3)$ & $44(65.7)$ & \multirow[t]{3}{*}{0.000} \\
\hline Central & $163(58.8)$ & $114(41.2)$ & \\
\hline Western & $79(67.5)$ & $38(32.5)$ & \\
\hline \multicolumn{4}{|l|}{ Insurance status } \\
\hline Insured & $188(58.0)$ & $136(42.0)$ & \multirow[t]{2}{*}{0.718} \\
\hline Uninsured & $77(56.2)$ & $60(43.8)$ & \\
\hline \multicolumn{4}{|l|}{ Plasmodium species } \\
\hline Unclassified & $43(71.7)$ & $17(28.3)$ & \multirow[t]{6}{*}{0.006} \\
\hline Plasmodium falciparum & $147(51.4)$ & $139(48.6)$ & \\
\hline Plasmodium ovale & $63(68.5)$ & $29(31.5)$ & \\
\hline Plasmodium vivax & $7(46.7)$ & $8(53.3)$ & \\
\hline Plasmodium malariae & $1(33.3)$ & $2(66.7)$ & \\
\hline Mixed & $4(80.0)$ & $1(20.0)$ & \\
\hline \multicolumn{4}{|l|}{ Rank of healthcare facilities for the initial diagnosis } \\
\hline Village clinic & $112(100.0)$ & $0(0.0)$ & \multirow[t]{8}{*}{0.000} \\
\hline Township health center & $18(100.0)$ & $0(0.0)$ & \\
\hline County-level CDC & $6(30.0)$ & $14(70.0)$ & \\
\hline Prefecture-level CDC & $6(40.0)$ & $9(60.0)$ & \\
\hline Provincial-level CDC & $1(50.0)$ & $1(50.0)$ & \\
\hline County-level hospital & $87(68.5)$ & $40(31.5)$ & \\
\hline Prefecture-level hospital & $27(21.3)$ & $100(78.7)$ & \\
\hline Provincial-level hospital & $8(20.0)$ & $32(80.0)$ & \\
\hline Time interval between onset and initial diagnosis & $1.6(1.3-1.9)$ & $2.7(2.3-3.1)$ & 0.000 \\
\hline
\end{tabular}

patients seeking care in township health centres and clinics was $100 \%$. The proportion of misdiagnosed patients seeking care in county-level hospitals dropped to about $70 \%$. Even for patients seeking care at different levels of CDC in China, the rate of misdiagnosis was still very high, which was far from the goal of the National Malaria Elimination Programme (NMEP) [31].

In 2010, the Chinese Government launched the NMEP (2010-2020) to enable malaria patients to receive timely treatment and reduce delays. Through this action plan, the government provided a large amount of funding to health facilities at all levels to train clinicians to perform blood tests for malaria parasites [32]. The survey year (2014-2016) was very close to 2020, and the goal of this year 2020 was to equip health workers at all levels of facilities with the capacity to diagnose and treat malaria patients. However, according to this investigation, it was observed that even though the National Health 
Table 4 Influential factors for complications developed among the malaria cases

\begin{tabular}{|c|c|c|c|}
\hline \multirow[t]{2}{*}{ Influential factors } & \multicolumn{2}{|c|}{$\begin{array}{l}\text { Complications developed } \\
(\% \text { or } 95 \% \mathrm{Cl})\end{array}$} & \multirow[t]{2}{*}{$P$ value } \\
\hline & Yes & No & \\
\hline \multicolumn{4}{|l|}{ Gender } \\
\hline Male & $91(18.8)$ & $394(81.2)$ & \multirow[t]{3}{*}{0.793} \\
\hline Female & $2(22.2)$ & $7(77.8)$ & \\
\hline Age (years) & $38.8(36.9-40.8)$ & $38.2(37.3-39.2)$ & \\
\hline \multicolumn{4}{|l|}{ Marital Status } \\
\hline Married & $71(18.0)$ & $323(82.0)$ & \multirow[t]{2}{*}{0.363} \\
\hline Single/divorce/separated & $22(22.0)$ & $78(78.0)$ & \\
\hline \multicolumn{4}{|l|}{ Occupation } \\
\hline Agriculture & $23(13.5)$ & $147(86.5)$ & \multirow[t]{2}{*}{0.029} \\
\hline No-agriculture & $70(21.6)$ & $254(78.4)$ & \\
\hline \multicolumn{4}{|l|}{ Residence } \\
\hline Unban & $55(18.1)$ & $249(81.9)$ & \multirow[t]{2}{*}{0.503} \\
\hline Rural & $38(20.5)$ & $147(79.5)$ & \\
\hline \multicolumn{4}{|l|}{ Region } \\
\hline Eastern & $9(13.4)$ & $58(86.6)$ & \multirow[t]{3}{*}{0.000} \\
\hline Central & $84(27.2)$ & $225(72.8)$ & \\
\hline Western & $0(0.0)$ & $118(100.0)$ & \\
\hline \multicolumn{4}{|l|}{ Insurance status } \\
\hline Insured & $68(19.7)$ & $278(80.4)$ & \multirow[t]{2}{*}{0.472} \\
\hline Uninsured & $25(16.9)$ & $123(83.1)$ & \\
\hline \multicolumn{4}{|l|}{ Plasmodium species } \\
\hline Unclassified & $24(35.3)$ & $44(64.7)$ & \multirow[t]{6}{*}{0.000} \\
\hline Plasmodium falciparum & $61(19.8)$ & $247(80.2)$ & \\
\hline Plasmodium ovale & $6(6.3)$ & $89(93.7)$ & \\
\hline Plasmodium vivax & $2(13.3)$ & $13(86.7)$ & \\
\hline Plasmodium malariae & $0(0.0)$ & $3(100.0)$ & \\
\hline Mixed & $0(0.0)$ & $5(100.0)$ & \\
\hline \multicolumn{4}{|l|}{ Rank of healthcare facilities for the initial diagnosis } \\
\hline Village clinic & $36(28.1)$ & $92(71.9)$ & \multirow[t]{8}{*}{0.000} \\
\hline Township health center & $4(20.0)$ & $16(80.0)$ & \\
\hline County-level CDC & $3(13.6)$ & $19(86.4)$ & \\
\hline Prefecture-level CDC & $2(13.3)$ & $13(86.7)$ & \\
\hline Provincial-level CDC & $0(0.0)$ & $2(100.0)$ & \\
\hline County-level hospital & $11(8.1)$ & $125(91.9)$ & \\
\hline Prefecture-level hospital & $35(26.9)$ & $95(73.1)$ & \\
\hline Provincial-level hospital & $2(4.9)$ & $39(95.1)$ & \\
\hline \multicolumn{4}{|l|}{ Initial diagnosis } \\
\hline Misdiagnosis & $61(23.0)$ & $204(77.0)$ & \multirow[t]{2}{*}{0.008} \\
\hline Correct diagnosis & $26(13.3)$ & $170(86.7)$ & \\
\hline Time interval between onset and initial diagnosis & $1.4(0.9-2.0)$ & $2.1(1.8-2.4)$ & 0.030 \\
\hline Time interval between initial diagnosis and final diagnosis & $4.2(3.1-5.4)$ & $3.1(2.5-3.7)$ & 0.080 \\
\hline Time interval between onset and final diagnosis & $5.7(4.5-6.9)$ & $5.3(4.7-6.0)$ & 0.631 \\
\hline
\end{tabular}

Commission had rolled out RDTs to all levels of health institutions, neither public health institutions, such as CDCs nor hospitals could accurately diagnose malaria.
With the elimination of local malaria, clinicians at all levels of health institutions, especially those at or below county level, have not been exposed to malaria cases 


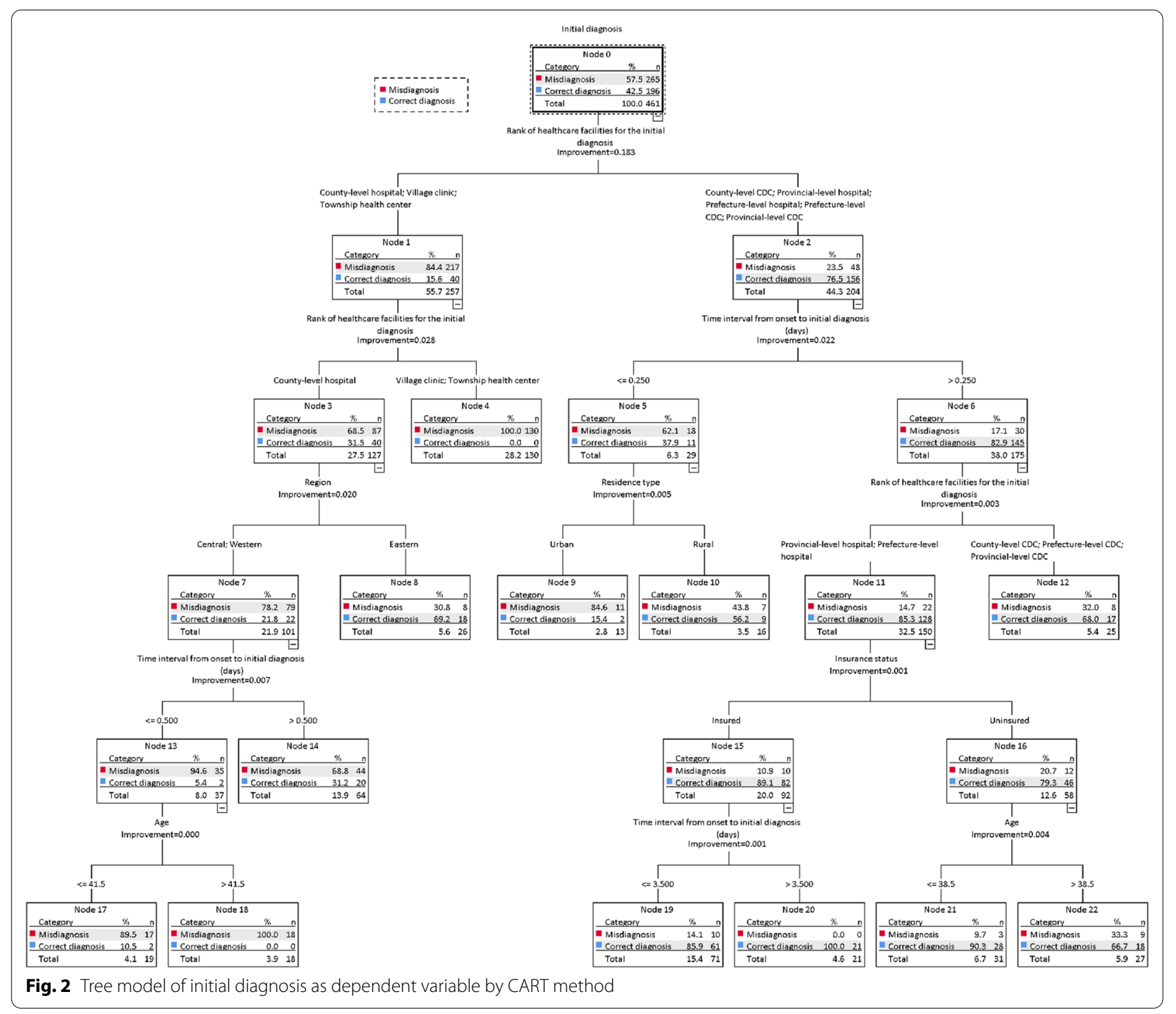

for a long time, which could have easily led clinicians to inaccurately diagnose malaria patients with fever as having common colds and neglecting to ask about their travel history [33, 34]. Moreover, it is also possible that these institutions may neither have the facilities required for diagnosis nor have physicians qualified to diagnose malaria [35]. Most cases were imported falciparum malaria in the years studied, particularly in regions bordering countries in Southeast Asia [36]; the patients were usually in serious condition $[37,38]$. Clinicians in health institutions at or below county level may use their experience to make a preliminary malaria diagnosis. However, accurate diagnosis requires microscopy tests and PCR. They would recommend patients to a higher-level hospital or CDC for further diagnosis and treatment.
It is noted that the time interval from the initial diagnosis to final diagnosis for patients seeking care initially in county-level hospitals, township health centres and clinics was longer than that of patients seeking care in higherlevel hospitals or CDCs. If a patient is diagnosed with malaria in time, clinicians could develop an appropriate treatment plan, which would significantly reduce the occurrence of complications and prevent the progression of the disease [3]. At the same time, it could reduce the cost of treatment and the economic burden on patients. The disparity in the time interval from initial diagnosis to final diagnosis for patients seeking care between different levels of health facilities should be noted. Patients living near higher-level hospitals usually have better access to timely and high-quality medical services than 
patients living in rural areas. In particular, diseases such as malaria are easily misdiagnosed as common colds [39]. If primary health institutions cannot make a correct diagnosis for patients from rural areas, it will greatly increase the probability of their condition worsening. After achieving the goal of eliminating malaria, it is necessary to build sustainable capacity of health workers and facilities at different levels to diagnose malaria, and establish a rapid referral system between primary care institutions and higher-level hospitals designated for malaria treatment in each prefecture-level area.

In this study, it was found that misdiagnosis rates between different regions varied greatly. Patients living in Western China were more likely to be misdiagnosed than those living in Eastern and Western China. The disparity of patients seeking care in different regions should be noted. Rural patients living in Western China, due to the inconvenience of transportation, usually sought care in nearby clinics and township health centres [25]. Due to insufficient diagnosis and treatment capabilities of local clinicians [21, 40], it was easy to cause patients to be misdiagnosed and delayed. There is a need to: allocate more anti-malarial funds to the western regions bordering countries in Southeast Asia; train qualified doctors in RDT techniques; and, educate communities and households in order to close the health gap between regions. The risk of resurgence of local transmission from imported malaria is not only a public health threat in China, but also in countries where malaria has been eliminated [41]. To maintain malaria-free status in regions where malaria transmission has been interrupted, crossborder collaborations with countries in the region will be beneficial. To consolidate progress in malaria eradication, it is necessary for China to strengthen its cooperation with Southeast Asia and African countries in malaria control and research [42].

\section{Limitations of the study}

This study has several limitations. First, some variables used in the analysis need to be extracted from the medical records. A limited number of hospitals surveyed can provide complete medical records. Patients with incomplete electronic medical records were excluded from this study. Second, some hospitals surveyed refused to provide medical records, thus the actual collected cases are smaller than expected. Third, as to whether a patient was correctly diagnosed, some clinicians may not rely on gold standard RDTs and microscopic examination but rely on personal experience to diagnose that the patient was infected with Plasmodium parasites and then referred the patient to a higher-level institution for further diagnosis. If, however, the clinician was unable to make a definite diagnosis, it was considered a misdiagnosis. The consequence is that misdiagnosis may be overestimated. Fourth, some variables, such as literacy level and self-care at home by patients may be associated with the timeliness of seeking care. However, due to the limitation of utilizing medical records, which did not provide such variables, the possible confounding effect of these variables were not explored. Finally, malaria cases date from 2014 to 2016, which were collected five years ago, and may not reflect the more recent situation.

\section{Conclusions}

Insufficient diagnostic capacity of healthcare facilities at lower administrative levels for the initial visit was the most important risk factor in diagnosing malaria patients. This study suggests that clinicians, government decision-makers, communities, and employers should consider comprehensively the healthcare facilities for an initial diagnosis, the time interval between onset and initial diagnosis, residence type, and health insurance status in order to reduce the misdiagnosis rate.

\section{Abbreviations \\ WHO: World Health Organization; NMEP: National Malaria Elimination Pro- gramme; RDTs: Rapid Diagnostic Tests; CDCs: Centers for Disease Control and Prevention.}

\section{Acknowledgements}

We would like to acknowledge the Disease Prevention and Control Bureau, National Health Commission of the People's Republic of China for their strong support of this study. The data collection was conducted with the help of the various Centers for Disease Control and Prevention in Zhejiang, Jiangsu, Anhui, Henan, Yunnan, and Sichuan. The authors would like to thank all the respondents for data collection and the staff in CDCs and health administrative departments for their assistance.

\section{Authors' contributions}

GL, ZCF and DLZ conceived and planed the study, SFT, GL and XYC collected the data, GL, ZC and XYC conducted the data analysis, GL, DLZ and ZC wrote the paper. ZC, SFT, DF and XYC commented and revised drafts of the manuscript. All authors read and approved the final manuscript.

\section{Funding}

This study was supported by the National Health Commission of PRC Project Malaria Elimination Assessment and Malaria Policy Analysis and the National Natural Science Foundation of China (Grant No. 72074088).

Availability of data and materials

The datasets used in the current study are available from the corresponding author and will also be presented as a supplemental file to the article.

\section{Declarations}

Ethics approval and consent to participate

Ethical approval was obtained from the Ethics Committee of Tongji Medical College, Huazhong University of Science \& Technology (IORG No: IORG0003571). Permission to access and analyze the research data was taken from the National Health Commission of People's Republic China and the administrators of each hospital.

Consent for publication

Not applicable. 


\section{Competing interests}

The authors declare that they have no competing interests.

\section{Author details}

${ }^{1}$ School of Medicine and Health Management, Tongji Medical College, Huazhong University of Science and Technology, 430030 Wuhan, Hubei, China. ${ }^{2}$ Department of Health Policy and Management, College of Public Health, University of Georgia, Athens, GA 30602, USA. ${ }^{3}$ School of Economics, University of Nottingham Ningbo China, Ningbo 531200, Zhejiang, China. ${ }^{4}$ School of Pharmacy, Tongji Medical College, Huazhong University of Science and Technology, Wuhan 430030, Hubei, China. ${ }^{5}$ Department of Epidemiology and Biostatistics, University of Georgia, Athens, GA 30602, USA.

\section{Received: 28 July 2021 Accepted: 3 December 2021}

Published online: 07 January 2022

\section{References}

1. Weiss DJ, Lucas TCD, Nguyen M, Nandi AK, Bisanzio D, Battle KE, et al. Mapping the global prevalence, incidence, and mortality of Plasmodium falciparum, 2000-17: a spatial and temporal modelling study. Lancet. 2019;394:322-31.

2. Battle KE, Lucas TCD, Nguyen M, Howes RE, Nandi AK, Twohig KA et al. Mapping the global endemicity and clinical burden of Plasmodium vivax, 2000-17: a spatial and temporal modelling study. Lancet. 2019;394:332-33.

3. WHO. World malaria report 2020. Geneva, World Health Organization, 2021. https://www.who.int/news-room/fact-sheets/detail/malaria. Accessed 14 Nov 2021

4. Hu T, Liu YB, Zhang SS, Xia ZG, Zhou SS, Yan J, Cao J, Feng ZC. Shrinking the malaria map in China: measuring the progress of the National Malaria Elimination Programme. Infect Dis Poverty. 2016;5:52.

5. Huang Q, Hu L, Liao QB, Xia J, Wang QR, Peng HJ. Spatiotemporal analysis of the malaria epidemic in mainland China, 2004-2014. Am J Trop Med Hyg. 2017;97:504-13.

6. Zhou S, Li Z, Cotter C, Zheng C, Zhang Q, Li H, et al. Trends of imported malaria in China 2010-2014: analysis of surveillance data. Malar J. 2016:15:39

7. Lai S, Sun J, Ruktanonchai NW, Zhou S, Yu J, Routledge I, et al. Changing epidemiology and challenges of malaria in China towards elimination. Malar J. 2019;18:107.

8. Feng J, Zhang L, Huang F, Yin JH, Tu H, Xia ZG, et al. Ready for malaria elimination: zero indigenous case reported in the People's Republic of China. Malar J. 2018;17:315.

9. Li Z, Zhang Q, Zheng C, Zhou S, Sun J, Zhang Z, et al. Epidemiologic features of overseas imported malaria in the People's Republic of China. Malar J. 2016;15:141.

10. Zhang SS, Feng J, Zhang L, Ren X, Geoffroy E, Manguin S, et al. Imported malaria cases in former endemic and non-malaria endemic areas in China: are there differences in case profile and time to response? Infect Dis Poverty. 2019;8:61.

11. Zhang Q, Geng Q, Sun J, Zhang Z, Lai S, Zhou S, Li Z. [Epidemiological analysis of the deaths of malaria in China, 2005-2014](in Chinese). Chinese J Prevent Med 2016; 50:302-305.

12. Zhang L, Feng J, Zhang S, Xia Z, Zhou S. [Malaria situation in the People's Republic of China in 2015.] (in Chinese). Chinese J Parasitol Parasit Dis. 2016;34:477-41.

13. WHO. Global technical strategy for malaria 2016-2030. Geneva, World Health Organization, 2021. https://www.who.int/publications/i/item/ 9789241564991. Accessed 20 Jul 2021

14. Amexo M, Tolhurst R, Barnish G, Bates I. Malaria misdiagnosis: effects on the poor and vulnerable. Lancet. 2004; 64:1896-8.

15. Landier J, Parker DM, Thu AM, Carrara VI, Lwin KM, Bonnington CA, et al. The role of early detection and treatment in malaria elimination. Malar J. 2016;15:363.

16. Tang S, Feng D, Wang R, Ghose B, Hu T, Ji L, et al. Economic burden of malaria inpatients during National Malaria Elimination Programme: estimation of hospitalization cost and its inter-province variation. Malar J. 2017;16:291.
17. Nankabirwa J, Zurovac D, Njogu JN, Rwakimari JB, Counihan H, Snow RW, et al. Malaria misdiagnosis in Uganda - implications for policy change. Malar J. 2009;8:66.

18. Parker DM, Carrara VI, Pukrittayakamee S, McGready R, Nosten FH. Malaria ecology along the Thailand-Myanmar border. Malar J. 2015;14:388.

19. Noor A, Zurovac D, Hay S, Ochola S, Snow R. Defining equity in physical access to clinical services using geographical information systems as part of malaria planning and monitoring in Kenya. Trop Med Int Health. 2003:8:917-26.

20. Sonkong K, Chaiklieng S, Neave P, Suggaravetsiri P. Factors affecting delay in seeking treatment among malaria patients along Thailand-Myanmar border in Tak Province, Thailand. Malar J. 2015;14:3.

21. Hänscheid T, Pinto BG, Pereira I, Cristino JM, Valadas E. Avoiding misdiagnosis of malaria: a novel automated method allows specific diagnosis, even in the absence of clinical suspicion. Emerg Infect Dis. 1999;5:836.

22. Allen LK, Hatfield JM, DeVetten G, Ho JC, Manyama M. Reducing malaria misdiagnosis: the importance of correctly interpreting Paracheck Pf ${ }^{\circledR \prime \prime}$ faint test bands" in a low transmission area of Tanzania. BMC Infect Dis. 2011;11:308.

23. Allen LK, Hatfield JM, Manyama MJ. Reducing microscopy-based malaria misdiagnosis in a low-resource area of Tanzania. Tanzan J Health Res. 2013;15:26-32.

24. Mfuh KO, Achonduh-Atijegbe OA, Bekindaka ON, Esemu LF, Mbakop CD, Gandhi K, et al. A comparison of thick-film microscopy, rapid diagnostic test, and polymerase chain reaction for accurate diagnosis of Plasmodium falciparum malaria. Malar J. 2019;18:73.

25. Wang X-L, Cao J-B, Li D-D, Guo D-X, Zhang C-D, Wang X, et al. Management of imported malaria cases and healthcare institutions in central China, 2012-2017: application of decision tree analysis. Malar J. 2019;18:429.

26. United Nations Children's Emergency Fund. Geographic regions of China. 2021. https://www.unicef.cn/en/figure-11-geographic-regions-china. Accessed 28 Jul 2021

27. Hartmann R, Wang Ja, Ye T. A comparative geography of China and the US. USA: New York: Springer; 2014.

28. Burns LR, Liu GG. China's healthcare system and reform. Cambridge University Press, 2017.

29. Kroese DP, Botev Z, Taimre T, Vaisman R. Data science and machine learning: mathematical and statistical methods. CRC Press; 2019.

30. De Ville B, Neville P. Decision trees for analytics: using SAS Enterprise miner. SAS Institute Cary, NC; 2013.

31. National Health Commission of the People's Republic of China. [Action plan of China Malaria Elimination (2010-2020)](in Chinese). Beijing, 2010. http://www.nhc.gov.cn/jkj/s5873/201005/f84f1 c4b0f32420990d23b65a 88e2d87.shtml. Accessed 22 Jul 2021

32. Feng J, Zhang L, Huang F, Yin J-H, Tu H, Xia Z-G, Zet al Ready for malaria elimination: zero indigenous case reported in the People's Republic of China. Malar J. 2018;17:315.

33. Romay-Barja M, Cano J, Ncogo P, Nseng G, Santana-Morales MA, Valladares $B$, et al. Determinants of delay in malaria care-seeking behaviour for children 15 years and under in Bata district, Equatorial Guinea. Malar J. 2016;15:187.

34. Zhang T, Xu X, Jiang J, Yu C, Tian C, Xie Q, et al. Risk factors of severe imported malaria in Anhui province, China. Acta Trop. 2019;197:104934.

35. Lai S, Li Z, Wardrop NA, Sun J, Head MG, Huang Z, et al. Malaria in China, 2011-2015: an observational study. Bull World Health Organ. 2017:95:564-73.

36. Lai S, Sun J, Ruktanonchai NW, Zhou S, Yu J, Routledge I, et al. Changing epidemiology and challenges of malaria in China towards elimination. Malar J. 2019;18:107.

37. Lin H, Lu L, Tian L, Zhou S, Wu H, Bi Y, et al. Spatial and temporal distribution of falciparum malaria in China. Malar J. 2009:8:130.

38. Bi Y, Hu W, Yang H, Zhou X-N, Yu W, Guo Y, Tong S. Spatial patterns of malaria reported deaths in Yunnan Province, China. Am J Trop Med Hyg. 2013;88:526-535

39. Demissie Y, Ketema T. Complicated malaria symptoms associated with Plasmodium vivax among patients visiting health facilities in Mendi town, Northwest Ethiopia. BMC Infect Dis. 2016;16:436.

40. Hänscheid T. Current strategies to avoid misdiagnosis of malaria. Clin Microbiol Infect. 2003; 9:497-504. 
41. Danis K, Baka A, Lenglet A, Van Bortel W, Terzaki I, Tseroni M, et al. Autochthonous Plasmodium vivax malaria in Greece, 2011. Eurosurveillance. 2011;16:19993.

42. Chen J-H, Fen J, Zhou X-N. From 30 million to zero malaria cases in China: lessons learned for China-Africa collaboration in malaria elimination. Infect Dis Poverty. 2021;10:51.

\section{Publisher's Note}

Springer Nature remains neutral with regard to jurisdictional claims in published maps and institutional affiliations.

- fast, convenient online submission

- thorough peer review by experienced researchers in your field

- rapid publication on acceptance

- support for research data, including large and complex data types

- gold Open Access which fosters wider collaboration and increased citations

- maximum visibility for your research: over 100M website views per year

At BMC, research is always in progress.

Learn more biomedcentral.com/submissions 